\title{
Modified Particle Swarm Optimization Based Proportional-Derivative Power System Stabilizer
}

\author{
Nader M.A. Ibrahim \\ Electrical Dept., Faculty of Industrial Education, Suez Univ., Suez, Egypt \\ E-amil: nader.abdelmohsen12@suezuniv.edu.eg
}

Hossam E. M. Attia

Member, IEEE, Electrical \& electronic engineering technology department at Jubail Industrial Collage (JIC), SA

E-mail: hossam.mostafa@ieee.org

Hossam E.A. Talaat

Electrical Power Eng. Dept., Ain Shams Univ., Cairo, Egypt

E-mail: hossam_talaat@eng.asu.edu.eg

Ali H. Kasem Alaboudy

Member, IEEE, Electrical Dept., Faculty of Industrial Education, Suez Univ., Suez, Egypt

\begin{abstract}
During a change in operating condition, oscillations of small magnitude and low frequency often persist for long periods of time and in some cases even present limitations on power transfer capability. Generators in power systems are equipped with automatic voltage regulator (AVR) to control terminal voltage. It is known that AVR has a detrimental impact upon the dynamic stability of the power system. Power system stabilizers (PSS) are widely used to generate supplementary control signals for the excitation system in order to damp out low-frequency oscillations (LFOs). In this paper proportionalderivative power system stabilizer (PD-PSS) used to damping LFO after tuning the gains of the PSS by using PSO. The damping boundary condition of PSO technique is modified to improve its performance in the tuning and optimization process. Simulation studies performed on a typical single-machine infinite-bus (SMIB) system used in MATLAB Simulink program. Assessing the performance of the proposed modified PSO based PD-PSS with Speed deviation $(\Delta \omega)$ as an input signal using eigenvalue analysis. The proposed PSO based PDPSS is evaluated and examined under different operating conditions and inertia constant each one of them applied with two test cases small disturbance and short circuit. A comparative study between the proposed PSO based PD-PSS, original PSO based PD-PSS, and lead-lag PSS is done in this work. The results ensure the superiority, the effectiveness, and the robustness of the proposed PSS over the other techniques.
\end{abstract}

Index Terms - PSS, PSO, single machine infinite bus, and damping LFO.

\section{NOMENCLATURE}

$\lambda_{1}$ : The electromechanical mode eigenvalue

$\Delta \delta$ : Rotor angle or power angle deviation, rad.

$\Delta \omega$ : Machine speed deviation, p.u.

$\omega_{0}:$ Rated speed $=2 \pi f_{0}$

$M$ : Inertia coefficient, Sec.

$H$ : Inertia constant
$D$ : Damping coefficient, p.u.

$K_{A}:$ AVR gain

$T_{A}:$ AVR time constant, Sec.

$T_{m}:$ Mechanical torque, p.u.

$T_{e}$ : Electrical torque, p.u.

$V_{\text {ref }}:$ Reference voltage, p.u.

$K_{1}-K_{8}$ : Constant coefficient

$E_{f d}:$ Generator field or exciter output voltage, p.u.

$X_{d}, X_{q}$ : Direct and quadratic axes reactance's of synchronous generator, p.u.

$X_{d}^{\prime}, X_{q}^{\prime}$ : Direct and quadratic axes transient reactance's of synchronous generator, p.u.

$T_{d o}^{\prime}$ : Open circuit direct axis time constant

$R_{e}$ : Equivalent resistance of transmission line, p.u.

$X_{e}$ : Equivalent reactance of transmission line, p.u.

$e_{0}$ : Voltage behind q-axis transient reactance, p.u.

Subscript (o): Stands for nominal or steady state value

$P_{0}$ : Electrical power, p.u.

$Q_{0}$ : Reactive power, p.u.

\section{INTRODUCTION}

With the rising of the electric power demand, while a power system is a highly nonlinear, large scale multiinput multi-output (MIMO), and dynamical system including numerous variables, protection devices, and control loops, with different dynamic responses and characteristic. Power system can reach stressed conditions due to the need for operating closer to their stability limits [1,2].

With the advent of interconnection of large electric power systems, many dynamic power system problems 
have emerged, which include power system Low Frequency Oscillations (LFO's) in the range 0.1-5HZ. The LFO's are generally affected by control action taken in the systems and are acceptable as long as they decay. Oscillations may not be troublesome themselves but have associated voltage or frequency swings that are not acceptable. These oscillations may be sustained for minutes, and grow to cause system separation. LFO's can also arise during normal steady-state operation.

LFOs have unwanted effects for modern power systems. These effects range from degradation of power quality up to disruptive effects on system electrical and mechanical components. It may grow leading to separation of interconnected systems especially in the absence of sufficient damping and synchronizing torque or even the presence of negative damping that causes cascaded outage of power system items [3, 4].

LFOs may persist in the power system for a long period and so affect the power transfer capabilities of the system so that the AVR not sufficient for the machine operating in a large electric power system. Therefore, supplementary damping must be sought. Power system stabilizer (PSS) were developed to aid in damping these oscillations by modulation of excitation system.

In the past few decades, considerable efforts have been devoted to the enhancement of power system stability. Currently most of the generators are equipped with rapidresponding high-gain voltage regulator for the excitation systems to automatically control the terminal voltage, although the transient stability of the power system can be improved by increasing the synchronizing torque of synchronous machines. It is known that the generator voltage regulator action poses a detrimental impact upon the dynamic stability of the power system. To offset this effect and to improve the system damping in general, supplementary stabilizing signals are introduced through conventional power system stabilizer (CPSS) [5].

CPSS was first proposed in the 1950's based on a linear model of the power system at some operating point to damp the LFO in the system. This type of PSS has made a great contribution in enhancing the operating quality of power system. The performance of CPSS is limited due to the effects of uncertainties such as parameter variations, external disturbances, and operating points change. Linear control theory was employed as the design tool for the CPSS as shown in [6-9].

With the development of power systems and increasing demand for quality electricity, it is worthwhile looking into the possibility of using modern control techniques [10]. The linear optimal control strategy is one possibility that has been proposed for supplementary excitation controllers, which showed promising results in damping of LFO, as illustrated in [11-14].

A more reasonable design of the PSS is on the adaptive control theory as it takes into consideration the non-linear and stochastic characteristic in power system. This type of stabilizer can adjust its parameter online according to the operating condition [15]. Huge number of papers has been published using this technique [16-21].
Adaptive control is based on the idea of continuously adapting the controller parameters according to recent measurements. However, the performance of adaptive controllers may be unsatisfactory during the learning phase, particularly when they are improperly initialized. Successful operation of adaptive controllers requires the measurements to satisfy persistence of excitation conditions, otherwise the adjustment of the controller parameters fails. Moreover, the design of nonlinear adaptive controllers may be complicated, and the selection of the adaptation gains which assure closed stability may require extensive calculations. Recently, alternative control schemes have been proposed to deal with the nonlinearity and uncertainties in power systems $[15,22]$. These are intelligent control schemes such as Artificial Neural Networks (ANN's) or fuzzy logic, which showed promising results in the PSS problem [2328]. Particle swarm optimization (PSO) also used widely in power system control. Reference [29] presents method for harmonic suppression using PSO based PI controller (PSOPI) to estimate an efficient shunt active power filter (SAPF). Reference [30] presents the using of PSO to optimize economic load dispatch (ELD) problem which is a common task in the operational planning of a power system. Reference [31] presents discrete PSO optimization approach used to optimize the placement and sizing processes of distributed generations (DG) and capacitors in distribution systems for simultaneous voltage profile improvement, loss and total harmonic distortion (THD) reduction.

The CPSS, because of its functional simplicity, is widely used in industrial applications. However, their parameters are often tuned using experience or trial and error methods. Unfortunately, it has been quite difficult to properly tune of CPSS gains because many industrial systems are often burdened with problems such as structure complexity, uncertainties and nonlinearities. Over the years, many different parameter tuning methods have been presented for CPSS controllers [2, 32, and 35].

In the present paper, PSO technique with modified damping boundary condition is used to tune the gains of the PD-PSS, which utilize with Speed deviation $(\Delta \omega)$ as an input signal. Eigenvalues and damping ratio indices are used in the optimization procedure. The proposed design approach was applied to a single machine infinite bus system in MATLAB Simulink program. The eigenvalue analysis, damping ratio and simulation results were carried out to examine the performance of PSS and to assess the effectiveness of the proposed PD-PSS with these signal to damp out the electromechanical modes of oscillations and enhance the dynamic stability of power systems.

The rest of the paper is organized as follows: In Section II Single machine infinite bus (SMIB) model. In section III power system stabilizer (PSS) design. In Section IV modified damping boundary condition in PSO. In Section V Simulation results. Finally, in Section VI Conclusion 


\section{SMIB MODEL}

\section{A. Linear model}

The system considered in this paper is a synchronous machine connected to an infinite bus through short transmission line as shown in Fig. 1. In order to design a robust power system controller, it is first necessary to consider an appropriate linear mathematical description of the single machine infinite bus power system model to get the block diagram of the system, which indicated in [36].

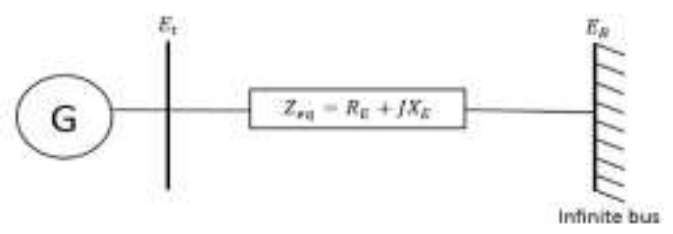

Fig. 1. Single machine connected to an infinite bus.

The state space representation is presented in [10]. In this system, the synchronous generator is described by a fourth-order model. The relations in the block diagram shown in Fig. 2. Apply to a direct and quadrature axes machine representation with a field circuit in the direct axis but without damper windings.

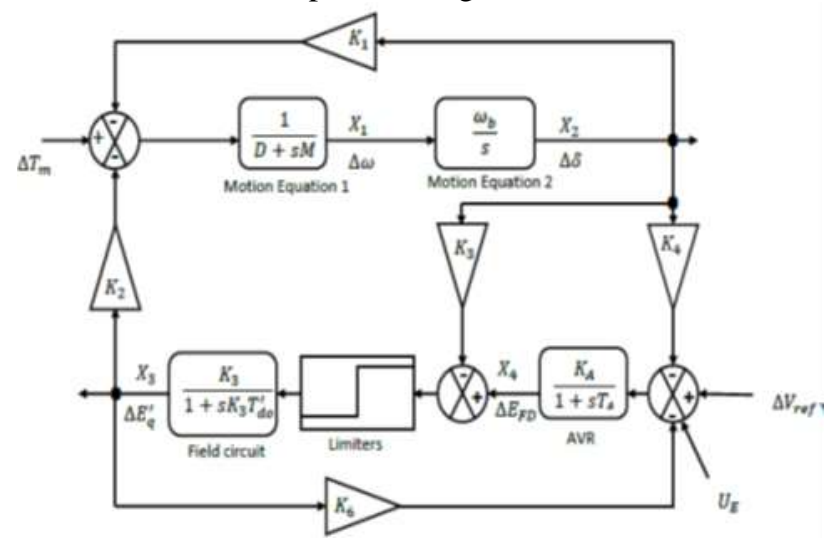

Fig. 2. System block diagram.
The interaction between the speed and voltage control equations of the machine is expressed in terms of six constants $\left(K_{1}: K_{6}\right)$. The constants are dependent upon the actual real and reactive power loading as well as the excitation levels in the machine, exception of $K_{\mathrm{a}}$ which is only a function of the ratio of the impedance [10].

The block diagram of the model used for PSS design as in $[4,36]$. The calculation of the constants illustrated in [32]. The complete data of the model is given from in [39]. The data of the model after manipulation is in Appendix A. The equations of the linear SMIB model without the proposed PD-PSS: -

$$
\begin{aligned}
& X_{1}=-\frac{D}{M} X_{1}-\frac{K_{1}}{M} X_{2}-\frac{K_{2}}{M} X_{3} \\
& X_{2}=\omega_{b} X_{1}
\end{aligned}
$$

Where, states:

$$
X=\left\lfloor\begin{array}{llll}
\Delta \omega & \Delta \delta & \Delta E_{q}^{\backslash} & \Delta E_{f d}
\end{array}\right\rfloor
$$

The eigenvalues of the system before adding the PDPSS signal for the light loading operating point and system parameters are shown in Table 1.

Table 1. The Eigenvalue of the SMIB System without PSS.

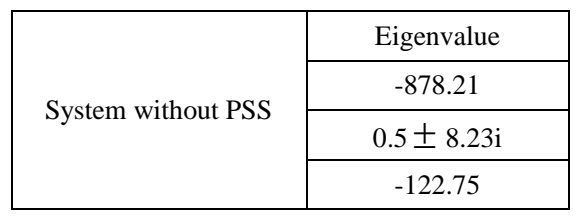

It is seen that from the table the system without using PSS is unstable.

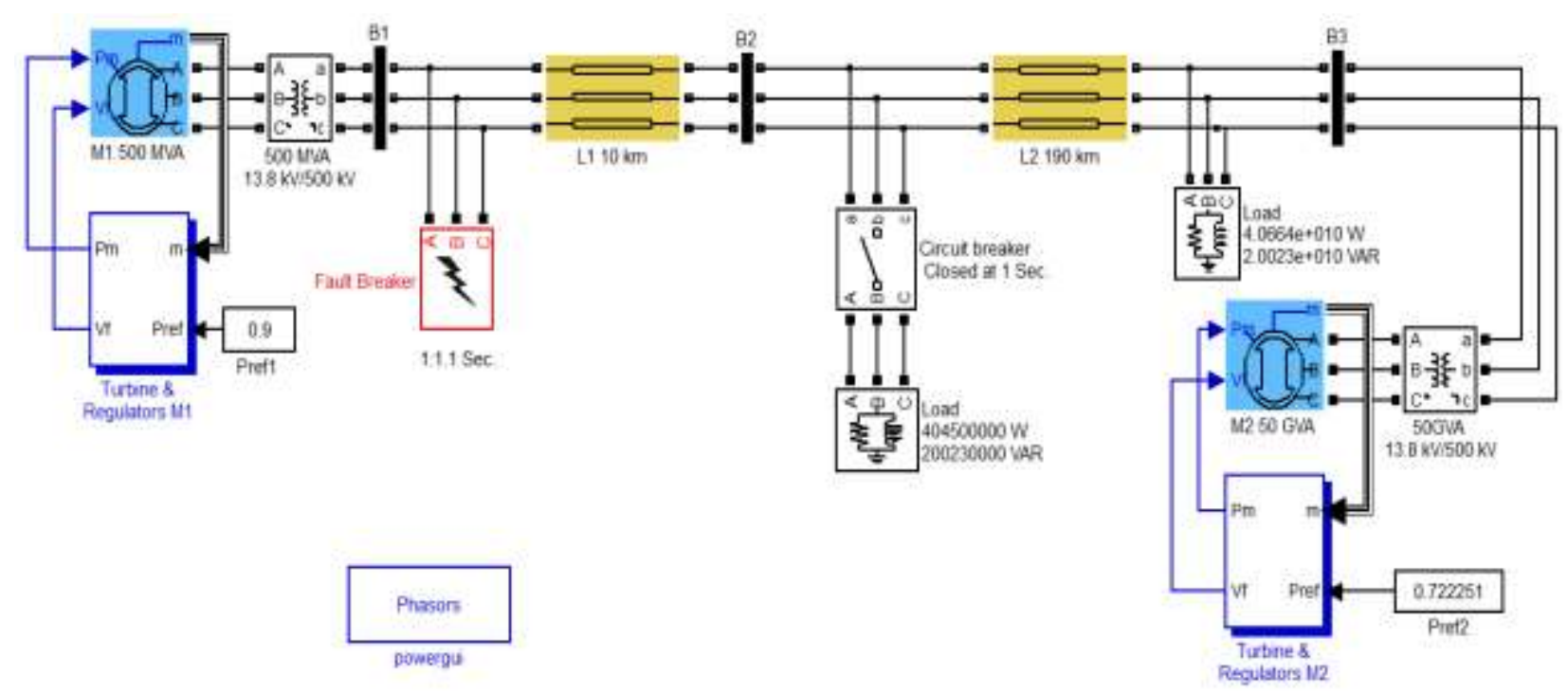

Fig. 3. Simulink model. 


\section{B. Study system}

In the design, some practical considerations are neglected so that the system block diagram shouldn't use in testing the developed PSS. From the previous reasons, a Simulink MATLAB model shown in Fig. 3., used for testing the developed PSS. The Simulink model is a MATLAB tutorial, its name is "transient stability of a two-machine transmission system with PSSs and static variation compensator (SVC)", and this demo is modified to become SMIB system as follow: -

a) Eliminating the SVC.

b) Increasing the complex power of the machine (2) from 5GVA to 50GVA, to be as infinite bus. Decreasing the complex power of the machine (1) from 1GVA to 5MVA, so that the machine (2) will be 100 times the machine (1).

c) Decreasing the length of the transmission line from $700 \mathrm{~km}$ to $200 \mathrm{~km}$.

d) Replacing the default PSS in the demo from the two machines by PD-PSS on machine (1) only, but machine 2 still without PSS.

e) Optimizing it by using modified system parameter.

f) The transmission line length is $200 \mathrm{~km}$.

g) The transmission line length between the small load, which 0.01 of the full load and the machine M1 is $10 \mathrm{~km}$.

The two generators are hydro with 32 salient pole pairs in the rotor. Investigating and testing of the developed PSS will be based on a nonlinear detail and practical considerations as nonlinearity, limiters, detailed machine model.

\section{PSS DESIGN}

The configuration of PD-PSS is shown in Fig. 4. While the speed deviation $(\Delta \omega)$ used as the input signal to the PSS. $T_{7}, T_{8}$ Time constants are assumed to be $0.05 \mathrm{~S}$. A Particle Swarm Optimization Toolbox (PSOt) is used in MATLAB scientific programming environment has been developed in [37, 38]. PSOt is employed to get the optimal values of $K_{7}, K_{8}$ parameters according to the given predefined ranges.

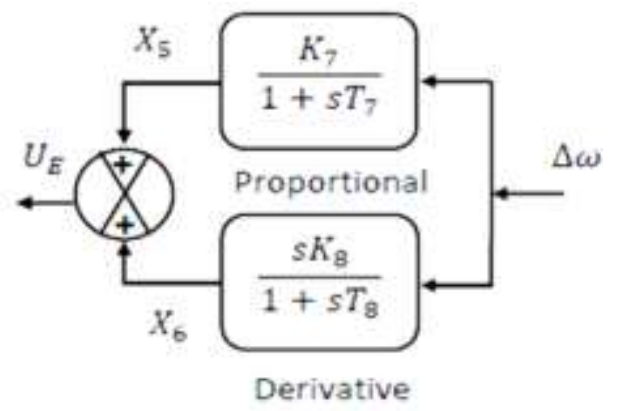

Fig. 4. PD-PSS configuration.

In addition to the main original PSO program, additional $\mathrm{m}$-file was designed based on the state-space of the linearization model to get the Eigen-values of the system. Objective functions are used to increase the system damping, by shifting all eigenvalues to the left side of the S-plane, that happened by either using $J_{1}$ to minimizing the settling time of the dominant Eigen-value or using $\mathrm{J}_{2}$ to maximizing the damping ratio of the dominant Eigen-value. The Eigen-value based objective functions are based as follow:

$$
\begin{aligned}
& J_{1}=\max \left\{\operatorname{Re} a l\left(\lambda_{i}\right)\right\} \\
& J_{2}=\min \{\text { Damping ratio }\}
\end{aligned}
$$

In the optimization process, it is aimed to minimize (J1), or maximize (J2) in order to shift the poorly damped eigenvalues to the left side in S-plane. Typical ranges of the optimized parameters are $(-100: 100)$ for all gains. The system (A) matrix after adding the stabilizing signal becomes:

$$
A=\left[\begin{array}{cccccc}
\frac{-D}{M} & \frac{-K_{1}}{M} & \frac{-K_{2}}{M} & 0 & 0 & 0 \\
w_{b} & 0 & 0 & 0 & 0 & 0 \\
0 & \frac{-K_{4}}{T_{d o}^{\prime}} & \frac{-1}{T_{d o}^{\prime} K_{a}} & \frac{1}{T_{d o}^{\prime}} & 0 & 0 \\
0 & \frac{-K_{A} K_{5}}{T_{A}} & \frac{-K_{A} K_{6}}{T_{A}} & \frac{-1}{T_{A}} & \frac{K_{A}}{T_{A}} & \frac{K_{A}}{T_{A}} \\
\frac{K_{7}}{T_{7}} & 0 & 0 & 0 & \frac{-1}{T_{7}} & 0 \\
0 & \frac{-K_{1} K_{8}}{T_{8} M} & \frac{-K_{2} K_{8}}{T_{8} M} & 0 & 0 & \frac{-1}{T_{8}}
\end{array}\right]
$$

There are two PD-PSS with the same configuration optimized by PSO, one of them is optimized by using the original PSO file which coming in the PSOt WinZip file, and the second PSS is the proposed PD-PSS which optimized by using the same PSO file, but modified its damping boundary condition to obtain the amplitude of $K_{7}, K_{8}$. The modified damping boundary condition of the PSO file will make the file more reliable, robust and faster than the original PSO file.

\section{MODIFIED DAMPING BOUNDARY CONDITION IN PSO}

Many modifications have been introduced to the original PSO technique to improve its searching for the optimum solution [40, 41]. In many practical optimization problems, the dimensionality and the location of the global optimum are usually difficult to know a priori. It is, therefore, desirable to have a single boundary condition that can offer a robust and consistent performance for the PSO technique regardless of the problem dimensionality and the location of the global optimum.

Reference [41] proposes a hybrid damping boundary condition that combines features of both the characteristics offered by the absorbing and reflecting walls. With this proposed damping boundary condition, whenever a particle tries to escape the search space in any one of the dimensions, part of the velocity in that 
dimension is absorbed by the boundary and the particle is then reflected back to the search space with a damped velocity along with a reversal of sign, as shown in Fig. 5.

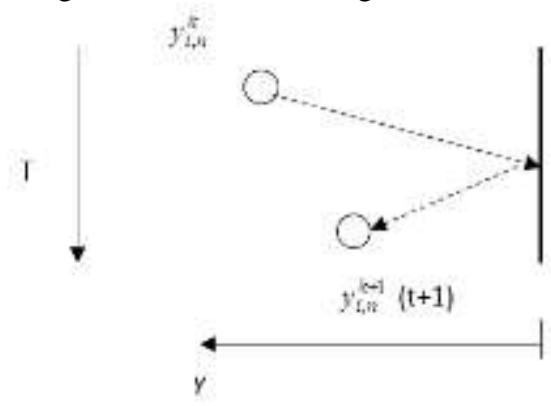

Fig. 5. Damping boundary: part of the velocity is absorbed by boundary and the particle is then reflected back with a lesser velocity.

This can be implemented in a very straightforward manner. First, determine the magnitude and sign of the velocity for the reflected particle, then multiply the velocity by a damping factor, $\Delta d$ which is a random variable uniformly distributed between $[0,1]$ to create the damping effect. Since $\Delta d$ is a uniformly distributed random variable between $[0,1]$, the behavior of the proposed damping boundary will lie in between the performances of the absorbing and reflecting boundaries [41]. It will act as the absorbing or reflecting boundary depending on the value of $\Delta d$ equal to zero or one respectively. In terms of equations, the updated velocity of the dampened particle can be expressed as: -

$$
v_{i, n}^{k+1}=\Delta d *-v_{i, n}^{k+1}
$$

Where, $-v_{i, n}^{k+1}$ is the velocity of the reflected particle as if the reflecting boundary were imposed at the boundary of the search space. In this paper, we choose the damping boundary condition to apply it for our problem.
The parameters $K_{7}, K_{8}$ amplitude of the first PD-PSS which optimized by the original PSO file: -

$$
K_{7}=20.7765, K_{8}=6.7036
$$

The amplitude of $K_{7}, K_{8}$ parameter of the proposed PD-PSS which obtained and optimized by the modified PSO file: -

$$
K_{7}=29.0501, K_{8}=9.5842
$$

\section{Simulation Results}

To verify the robustness of the proposed modified PSO based PD-PSS, three different operating points are proposed to test the stabilizers. Also, different inertia constant is proposed to test the system under study. Eight study cases are developed on the study system equipped the proposed modified PSO based PD-PSS and the original PSO based PD-PSS.

Another eight study cases are developed and tested when the study system is equipped with conventional lead-lag compensator (CPSS) which designed on the same power system at nominal operating point by using the method of Ref. [3]. A comparison between the proposed modified PSO based PD-PSS, the original PSO based PD-PSS, and the lead-lag PSS to show the superiority of the proposed PSS. The eight study cases are three different loading conditions with inertia constant $3.7 \mathrm{Sec}$. The fourth study case is the system with $2.5 \mathrm{Sec}$., inertia constant at normal operating condition. Each case of the study cases are tested with: -

A) $0.01 \mathrm{Small}$ disturbance in the load.

B) 6-Cycles three phase Short circuit near the bus B1.

The sequence of the study and test cases are showed in Table 2.

Table 2. The Sequence of the Study Cases and the Test Cases

\begin{tabular}{|c|c|}
\hline Study cases & Test cases \\
\hline Normal loading operating condition. \\
$\mathrm{P}=0.9 \mathrm{Q}=0.1464$ With inertia constant=3.7Sec. & $\begin{array}{c}\text { Small disturbance. } \\
\text { Short circuit. }\end{array}$ \\
\hline $\begin{array}{c}\text { Heavy loading operating condition. } \\
\mathrm{Q}=0.167 \text { With inertia constant=3.7Sec. }\end{array}$ & $\begin{array}{c}\text { Small disturbance. } \\
\text { Short circuit. }\end{array}$ \\
\hline $\mathrm{P}=0.6 \mathrm{Q}=0.1009$ With inertia constant=3.7Sec. & $\begin{array}{c}\text { Small disturbance. } \\
\text { Short circuit. }\end{array}$ \\
\hline Decreasing inertia constant from 3.7 to 2.5 Sec. at normal operating point. & $\begin{array}{c}\text { Small disturbance. } \\
\text { Short circuit. }\end{array}$ \\
\hline
\end{tabular}

Table 3. The Eigen-Values of the System with Different PSS at Nominal Loading.

\begin{tabular}{|c|c|c|c|}
\hline \multirow{7}{*}{ Eigen-values } & Lead-lag PSS & Original PSO based PD-PSS & Modified PSO based PD-PSS \\
\cline { 2 - 4 } & -880.57 & -885.53 & -887.77 \\
\cline { 2 - 4 } & -119.23 & $-66.96 \pm 39.28 \mathrm{i}$ & $-65.79 \pm 58.17 \mathrm{i}$ \\
\cline { 2 - 4 } & $-0.46 \pm 7.68 \mathrm{i}$ & $-1.5 \pm 5.01 \mathrm{i}$ & $-1.54 \pm 4.35 \mathrm{i}$ \\
\cline { 2 - 4 } & -11.72 & -20 & -20 \\
\cline { 2 - 4 } & -0.33 & - & - \\
\hline
\end{tabular}

The study cases as shown in the previous table divided into four cases each one of them contains two tests as follow: -

\section{A. Normal loading condition}

I.J. Intelligent Systems and Applications, 2015, 03, 62-76 
The optimization processing by PSO is depending upon this operating condition, and the design of the leadlag compensator CPSS depend on this operating condition. This study case is applied in the system when equipped with lead-lag PSS, original PSO based PD-PSS, modified PSO based PD-PSS, and without PSS. The Eigen-values of the system without PSS and with CPSS, original PSO based PD-PSS, and modified PSO PD-PSS are shown in Table 3.

Normal operating condition divided into two type of tests as follow: -

\section{Small disturbance}

A small disturbance is simulated by applying $1 \%$ load step change of the full load is subjected at $1 \mathrm{Sec}$. The system responses to this disturbance when the generator M1 equipped without PSS and with lead-lag PSS, original PSO based PD-PSS, and modified PSO based PD-PSS, when using the speed deviation of the generator M1 are shown in fig. 6 .

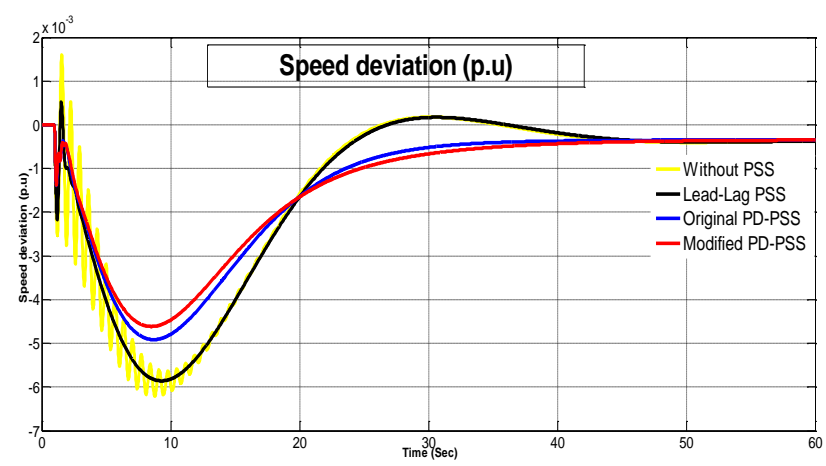

Fig. 6. Rotor speed deviation response of the system without PSS and with different PSS to $1 \%$ load step change at nominal loading.

The maximum overshoot, the settling time, and the area under curve of the speed deviation responses of the system with different PSS and without PSS are shown in Table 4.

Table 4. The Rotor Speed Deviation Responses to Load Step Change 0.01 at Normal Loading Condition when the System Equipped with Different PSSs and without PSS.

\begin{tabular}{|c|c|c|c|c|}
\hline parameter & Without PSS & Lead-lag PSS & Original PD-PSS & Modified PD-PSS \\
\hline Max. overshoot & $1.6074 \mathrm{e}+3$ & $1.4864 \mathrm{e}+3$ & $1.3264 \mathrm{e}+3$ & $1.2233 \mathrm{e}+3$ \\
\hline Settling time & 40.8713 & 42.0241 & 33.1567 & 39.9792 \\
\hline Area under curve & -0.0853 & -0.0853 & -0.0831 & -0.822 \\
\hline
\end{tabular}

The rotor speed deviation response of the system and its details in the table indicate that the system equipped with modified PSO based PD-PSS is more reliable and faster than the other in damping the LFOs with lower Maximum overshoot. The active power responses of the system when generator M1 equipped with different PSS to 0.01 load step change shown in Fig. 7.

The maximum overshoot, the settling time, and the area under curve of the power active system responses when generator M1 equipped with different PSS, which shown in the above figure are shown in Table 5.

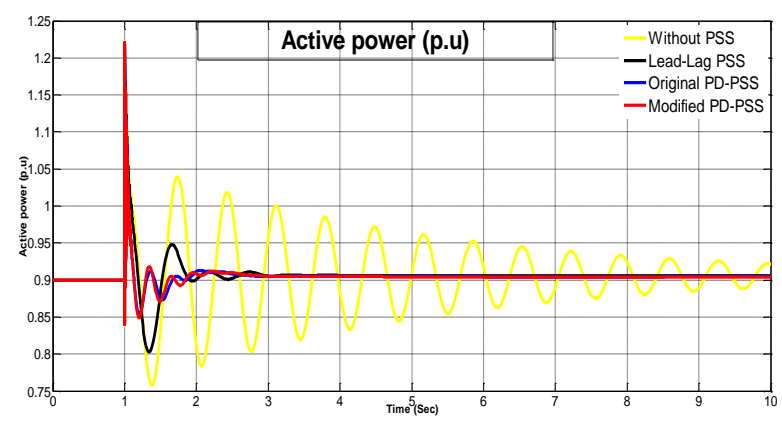

Fig. 7. Active power response of the system without PSS and with different PSS to 0.01 load step change at nominal loading.

Table 5. The Active Power Responses to Load Step Change 0.01 at Normal Loading Condition when the System Equipped with Different PSSs and without PSS

\begin{tabular}{|c|c|c|c|c|}
\hline Parameter & Without PSS & Lead-lag PSS & Original PD-PSS & Modified PD-PSS \\
\hline Max. overshoot & 1.2214 & 1.2178 & 1.2188 & 1.2211 \\
\hline Settling time & - & 1.9855 & 2.3812 & 0.9041 \\
\hline Area under curve & 9.0555 & 9.0547 & 9.0447 & 9.0403 \\
\hline
\end{tabular}

It can be seen from (Fig. 7., and Table 5. ) that the proposed Modified PSO based PD-PSS is the most effective controller, improve the stability of the system with the lowest settling time and area under curve, and damp the LFOs faster than the other controller.

\section{Three phase short circuit}

A three phase short circuit to ground is applied to the system near to the generator M1 when the generator M1 is equipped with no PSS, CPSS, original PSO based PDPSS, and modified PSO based PD-PSS. The short circuit applied at $1 \mathrm{Sec}$. and removed at $1.1 \mathrm{Sec}$.

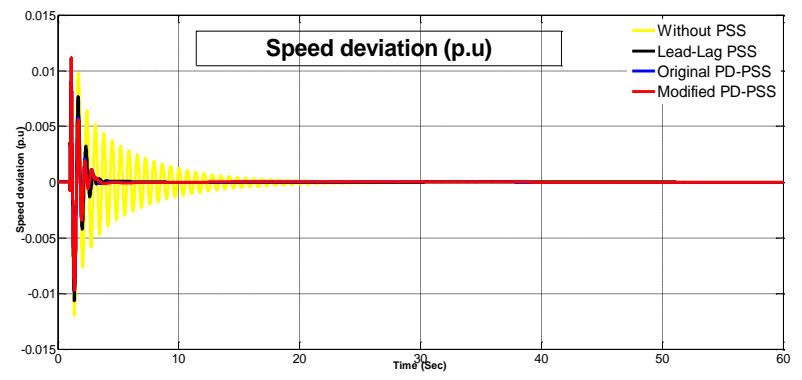

Fig. 8. Rotor speed deviation responses of the system without PSS and with different PSS to 6-cycles three phase short circuit at nominal loading. 
So that the short circuit is three phase 6-cycles. Figure 8. Shown rotor speed deviation system response of machine M1 when this generator equipped with no PSS and lead-lag PSS, original PSO based PD-PSS, and modified PSO based PD-PSS.
The maximum overshoot, the settling time, and the area under curve of the power active system responses when generator M1 equipped with different PSS, which showed in the above figure are shown in Table 6.

Table 6. The Rotor Speed Deviation Responses to 6-Cycles Three Phase Short Circuit near Generator M1 at Nominal Loading when the System Equipped with Different PSSs and without PSS.

\begin{tabular}{|c|c|c|c|c|}
\hline Parameter & Without PSS & Lead-lag PSS & Original PD-PSS & Modified PD-PSS \\
\hline Max. overshoot & 0.0111 & 0.0111 & 0.0111 & 0.0111 \\
\hline Settling time & 18.7128 & 3.5364 & 3.2510 & 3.3119 \\
\hline Area under curve & $3.8358 \mathrm{e}-5$ & $3.5906 \mathrm{e}-5$ & $7.0020 \mathrm{e}-7$ & $-6.6180 \mathrm{e}-7$ \\
\hline
\end{tabular}

It can be seen that from (Fig. 8. and Table 6.) that all the maximum overshoot and the settling time almost the same but the proposed modified PSO based PD-PSS have the smallest area under curve which make the system faster in damping the LFOs when equipped with the proposed PSS than the other PSS. Figure 9. Shown active power responses system responses of machine M1 when this generator equipped with no PSS and Lead-lag PSS, original PSO based PD-PSS, and modified PSO based PD-PSS.

The maximum overshoot, the settling time, and the area under curve of the power active system responses when generator M1 equipped with different PSS, which showed in the above figure are shown in Table 7.

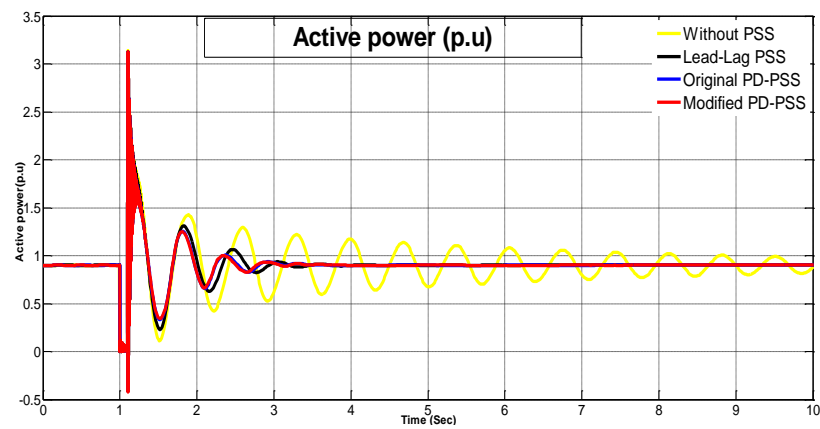

Fig. 9. Active power response of the system without PSS and with different PSS to 6-cycles three short circuit at nominal loading.

Table 7. The Active Power Responses to 6-Cycles Three Phase Short Circuit near Generator M1 at Nominal Loading when the System Equipped with Different PSSs and without PSS.

\begin{tabular}{|c|c|c|c|c|}
\hline Parameter & Without PSS & Lead-lag PSS & Original PD-PSS & Modified PD-PSS \\
\hline Max. overshoot & 3.1354 & 3.1229 & 3.1247 & 3.1267 \\
\hline Settling time & - & 2.8623 & 2.7442 & 2.7146 \\
\hline Area under curve & 8.9834 & 8.9935 & 8.9941 & 8.9941 \\
\hline
\end{tabular}

It can be seen that from (Fig. 9., and Table 7.) that all the maximum overshoot and the area under curve almost the same, but the proposed modified PSO based PD-PSS have the smallest settling time, which indicate that the proposed PSS is robust the other. Because the response of the system without PSS have far wares response from the other, so that system without PSS will be removed from the upcoming test and study cases in the paper.

\section{B. Heavy loading condition}

Heavy loading condition consist of the same two tests in the nominal loading condition when: -

$$
P_{0}=1 \text { p.u. }, \quad Q_{0}=0.167 \text { p.u. }
$$

The Eigen-values of the system when the generator M1 equipped with lead-lag PSS, original PSO based PD-PSS, and modified PSO based PD-PSS at heavy loading are shown in Table 8.

Table 8. The Eigen-Values of the System with Different PSS at Heavy Loading

\begin{tabular}{|c|c|c|c|}
\hline \multirow{4}{*}{ Eigen-values } & Lead-lag PSS & Original PSO based PD-PSS & Modified PSO based PD-PSS \\
\cline { 2 - 4 } & -882.58 & -887.90 & -890.32 \\
\cline { 2 - 4 } & -116.97 & $-65.74 \pm 44.61 \mathrm{i}$ & $-64.50 \pm 63.09 \mathrm{i}$ \\
\cline { 2 - 4 } & $-0.5 \pm 7.74 \mathrm{i}$ & $-1.53 \pm 4.9 \mathrm{i}$ & $-1.56 \pm 4.24 \mathrm{i}$ \\
\cline { 2 - 4 } & -11.88 & -20 & -20 \\
\cline { 2 - 4 } & -0.33 & - & - \\
\hline
\end{tabular}

The Eigen-values of the system with different PSS proved that the proposed PSS is more reliable and robust than the other PSS in damping the LFOs.

\section{Small disturbance}

A small disturbance is simulated by applying $1 \%$ load step change of the full load is subjected at $1 \mathrm{Sec}$. The system responses to this disturbance when the generator M1 equipped with lead-lag PSS, original PSO based PDPSS, and modified PSO based PD-PSS, when using the speed deviation of the generator M1 are shown in fig. 10. 


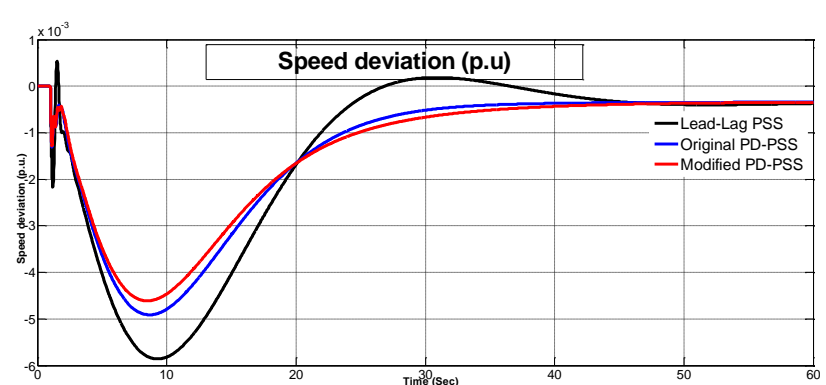

Fig. 10. Rotor speed deviation response of the system without PSS and with different PSS to $1 \%$ load step change at heavy loading.
The maximum overshoot, the settling time, and the area under curve of the speed deviation responses of the system with different PSS and without PSS are shown in Table 9.

Table 9. The Rotor Speed Deviation Responses to Load Step Change 0.01 at Heavy Loading Condition when the System Equipped with Different PSSs.

\begin{tabular}{|c|c|c|c|}
\hline parameter & Lead-lag PSS & Original PD-PSS & Modified PD-PSS \\
\hline Max. overshoot & $5.3616 \mathrm{e}-4$ & $4.7698 \mathrm{e}-7$ & $4.6010 \mathrm{e}-7$ \\
\hline Settling time & 42.4564 & 32.9675 & 35.0074 \\
\hline Area under curve & -0.0854 & -0.0831 & -0.0822 \\
\hline
\end{tabular}

The rotor speed deviation response of the system and its details in the table indicate that the system equipped with modified PSO based PD-PSS is more reliable and faster than the other in damping the LFOs with lower Maximum overshoot. The active power responses of the system when generator M1 equipped with different PSS to 0.01 load step change shown in Fig. 11 .

The maximum overshoot, the settling time, and the area under curve of the power active system responses when generator M1 equipped with different PSS, which showed in the above figure are shown in Table 10.

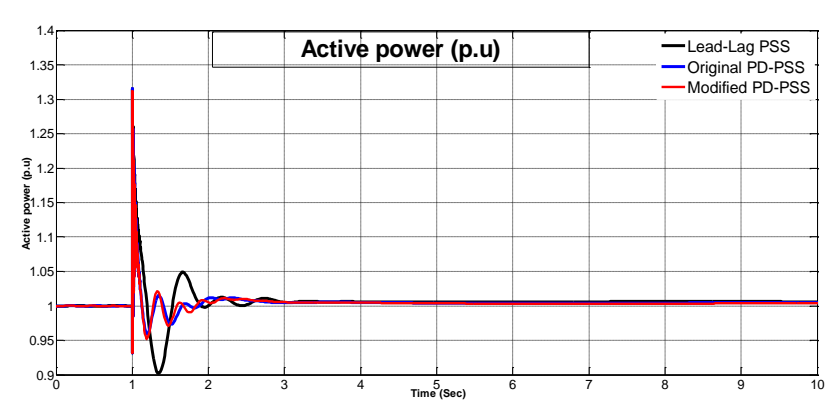

Fig. 11. Active power response of the system without PSS and with different PSS to 0.01 load step change at heavy loading.

Table 10. The Active Power Responses to Load Step Change 0.01 at Heavy Loading Condition when the System Equipped with Different PSSs.

\begin{tabular}{|c|c|c|c|}
\hline Parameter & Lead-lag PSS & Original PD-PSS & Modified PD-PSS \\
\hline Max. overshoot & 1.3154 & 1.3150 & 1.3118 \\
\hline Settling time & 2.2044 & 2.3748 & 2.2039 \\
\hline Area under curve & 10.0539 & 10.0423 & 10.0373 \\
\hline
\end{tabular}

It can be seen from (Fig. 11., and Table 10.) that the proposed Modified PSO based PD-PSS is the most effective controller, improve the stability of the system with the lowest settling time, area under curve, and lowest maximum overshoot. The proposed PD-PSS improve the stability of the system higher than the other.

\section{Three phase short circuit}

A three phase short circuit to ground is applied to the system near to the generator M1 when the generator M1 is equipped with no PSS, lead-lag PSS, default PSO based PD-PSS, and modified PSO based PD-PSS. The short circuit applied at $1 \mathrm{Sec}$. and removed at $1.1 \mathrm{Sec}$. So that the short circuit is three phase 6-cycles. Figure 12. Shown rotor speed deviation system response of machine M1 when this generator equipped with no PSS, CPSS, default PSO based PD-PSS, and modified PSO based PD-PSS.

The maximum overshoot, the settling time, and the area under curve of the power active system responses when generator M1 equipped with different PSS, which showed in the above figure are shown in Table 11.

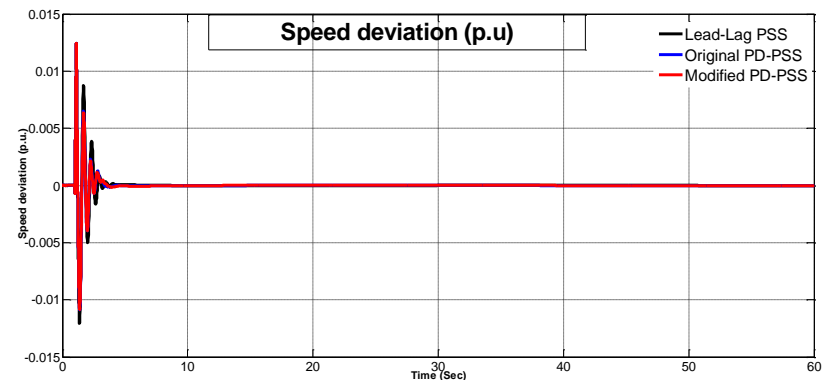

Fig. 12. Rotor speed deviation responses of the system without PSS and with different PSS to 6-cycles three phase short circuit at heavy loading.

It can be seen that from (Fig. 12., and Table 11.) that all the maximum overshoot and the settling time almost the same but the proposed modified PSO based PD-PSS have the smallest area under curve which make the system faster in damping the LFOs when equipped with the proposed PSS than the other PSS. Figure 13. Shown active power responses system responses of machine M1 when this generator equipped with no PSS, lead-lag PSS, original PSO based PD-PSS, and modified PSO based PD-PSS. 
Table 11. The Rotor Speed Deviation Responses to 6-Cycles Three Phase Short Circuit near Generator M1 at Heavy Loading when the System Equipped with Different PSSs.

\begin{tabular}{|c|c|c|c|}
\hline Parameter & Lead-lag PSS & Original PD-PSS & Modified PD-PSS \\
\hline Max. overshoot & 0.0124 & 0.0124 & 0.0124 \\
\hline Settling time & 3.5514 & 3.2744 & 3.2357 \\
\hline Area under curve & $3.5764 \mathrm{e}-5$ & $2.1269 \mathrm{e}-6$ & $-5.9053 \mathrm{e}-6$ \\
\hline
\end{tabular}

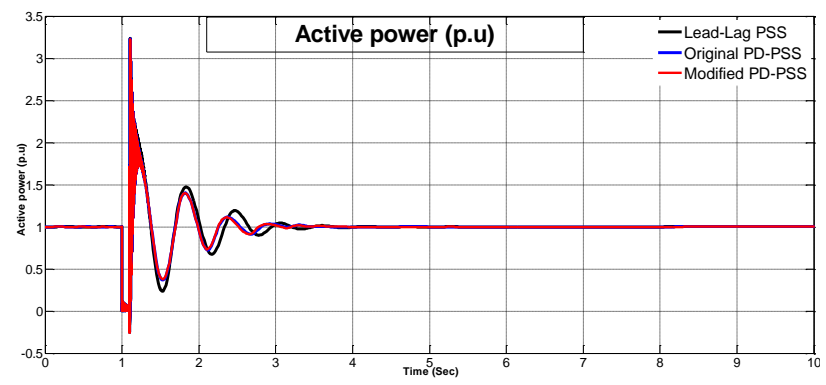

Fig. 13. Active power response of the system without PSS and with different PSS to 6-cycles three phase short circuit at heavy loading.
The maximum overshoot, the settling time, and the area under curve of the power active system responses when generator M1 equipped with different PSS, which showed in the above figure are shown in Table 12.

It can be seen that from (Fig. 13., and Table 12.) that all the area under curve almost the same, but the proposed modified PSO based PD-PSS have the smallest maximum overshoot and settling time, which indicate that the proposed PSS is robust than the other.

Table 12. The Active Power Responses to 6-Cycles Three Phase Short Circuit near Generator M1 at Heavy Loading when the System Equipped with Different PSSs.

\begin{tabular}{|c|c|c|c|}
\hline Parameter & Lead-lag PSS & Original PD-PSS & Modified PD-PSS \\
\hline Max. overshoot & 3.2360 & 3.2279 & 3.2219 \\
\hline Settling time & 2.8896 & 2.7591 & 2.7298 \\
\hline Area under curve & 9.9903 & 9.9915 & 9.9903 \\
\hline
\end{tabular}

\section{Light loading condition}

Light loading condition consist of the same two tests in the nominal and heavy loading conditions when: -

$$
P_{0}=0.6 p . u ., \quad Q_{0}=0.1009 \text { p.u. }
$$

The Eigen-values of the system when the generator M1 equipped with lead-lag PSS, original PSO based PD-PSS, and modified PSO based PD-PSS at heavy loading are shown in Table 13.

Table 13. The Eigen-Values of the System with Different PSS at Light Loading.

\begin{tabular}{|c|c|c|c|}
\hline \multirow{4}{*}{ Eigen-values } & Lead-lag PSS & Original PSO based PD-PSS & Modified PSO based PD-PSS \\
\cline { 2 - 4 } & -875.01 & -878.61 & -880.24 \\
\cline { 2 - 4 } & -125.62 & $-70.57 \pm 6.06 \mathrm{i}$ & $-69.66 \pm 36.77 \mathrm{i}$ \\
\cline { 2 - 4 } & $-0.31 \pm 7.56 \mathrm{i}$ & $-1.34 \pm 5.49 \mathrm{i}$ & $-1.44 \pm 48.7 \mathrm{i}$ \\
\cline { 2 - 4 } & -11.18 & -20 & -20 \\
\cline { 2 - 4 } & -0.33 & - & - \\
\hline
\end{tabular}

The Eigen-values of the system with different PSS proved that the proposed PSS is more reliable and robust than the other PSS in damping the LFOs.

\section{Small disturbance}

A small disturbance is simulated by applying $1 \%$ load step change of the full load is subjected at $1 \mathrm{Sec}$. The system responses to this disturbance when the generator M1 equipped with lead-lag PSS, original PSO based PDPSS, and modified PSO based PD-PSS, when using the speed deviation of the generator M1 are shown in fig. 14.

The maximum overshoot, the settling time, and the area under curve of the speed deviation responses of the system with different PSS and without PSS are shown in Table 14.

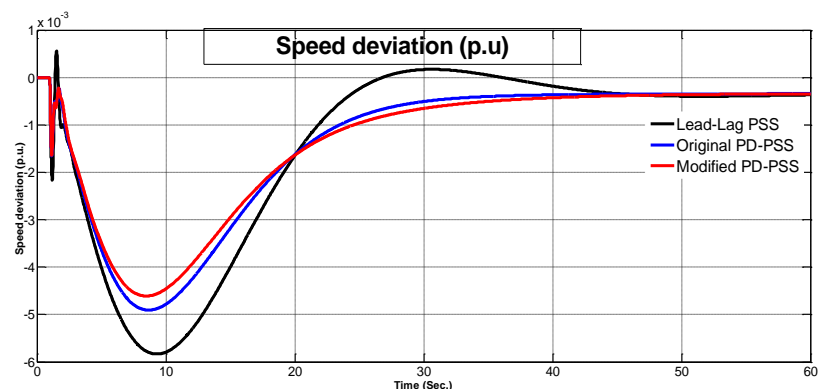

Fig. 14. Rotor speed deviation response of the system without PSS and with different PSS to $1 \%$ load step change at light loading.

The rotor speed deviation response of the system and its details in the table indicate that the system equipped with modified PSO based PD-PSS is more reliable and faster than the other in damping the LFOs with lower Maximum overshoot. The active power responses of the 
system when generator M1 equipped with different PSS

to 0.01 load step change shown in Fig. 15 .

Table 14. The Rotor Speed Deviation Responses to Load Step Change 0.01 at Light Loading Condition when the System Equipped with Different PSSs.

\begin{tabular}{|c|c|c|c|}
\hline parameter & Lead-lag PSS & Original PD-PSS & Modified PD-PSS \\
\hline Max. overshoot & $5.6229 \mathrm{e}-4$ & $5.2142 \mathrm{e}-7$ & $5.0504 \mathrm{e}-7$ \\
\hline Settling time & 42.0116 & 32.7632 & 33.5945 \\
\hline Area under curve & -0.0849 & -0.0828 & -0.0819 \\
\hline
\end{tabular}

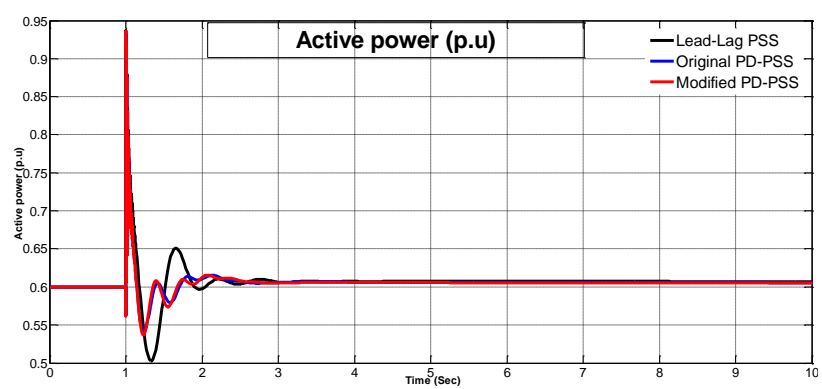

Fig. 15. Active power response of the system without PSS and with different PSS to 0.01 load step change at light loading.

The maximum overshoot, the settling time, and the area under curve of the power active system responses when generator M1 equipped with different PSS, which showed in the above figure are shown in Table 15.

Table 15. The Active Power Responses to Load Step Change 0.01 at Light Loading Condition when the System Equipped with Different PSSs.

\begin{tabular}{|c|c|c|c|}
\hline Parameter & $\begin{array}{c}\text { Lead-lag } \\
\text { PSS }\end{array}$ & $\begin{array}{c}\text { Original } \\
\text { PD-PSS }\end{array}$ & $\begin{array}{c}\text { Modified } \\
\text { PD-PSS }\end{array}$ \\
\hline $\begin{array}{c}\text { Max. } \\
\text { overshoot }\end{array}$ & 0.9369 & 0.9329 & 0.9364 \\
\hline $\begin{array}{c}\text { Settling } \\
\text { time }\end{array}$ & 2.4448 & 2.2403 & 2.1561 \\
\hline $\begin{array}{c}\text { Area under } \\
\text { curve }\end{array}$ & 6.0643 & 6.0549 & 6.0507 \\
\hline
\end{tabular}

It can be seen from (Fig. 15., and Table 15.) that the proposed Modified PSO based PD-PSS is the most effective controller, and improve the stability of the system with the lowest settling time, and area under curve. The proposed PD-PSS improve the stability of the system higher than the other.

\section{Three phase short circuit}

A three phase short circuit to ground is applied to the system near to the generator M1 when the generator M1 is equipped with no PSS, lead-lag PSS, original PSO based PD-PSS, and modified PSO based PD-PSS. The short circuit applied at $1 \mathrm{Sec}$. and removed at $1.1 \mathrm{Sec}$. So that the short circuit is three phase 6-cycles. Figure 16. Shown rotor speed deviation system response of machine M1 when this generator equipped with no PSS, lead-lag PSS, original PSO based PD-PSS, and modified PSO based PD-PSS.

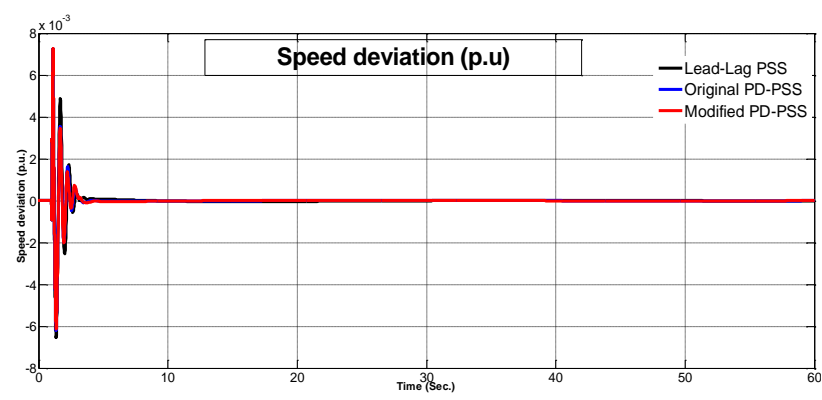

Fig. 16. Rotor speed deviation responses of the system without PSS and with different PSS to 6-cycles three phase short circuit at light loading.

The maximum overshoot, the settling time, and the area under curve of the power active system responses when generator M1 equipped with different PSS, which showed in the above figure are shown in Table 16.

Table 16. The Rotor Speed Deviation Responses to 6-Cycles Three Phase Short Circuit near Generator M1 at Light Loading when the System Equipped with Different PSSs.

\begin{tabular}{|c|c|c|c|}
\hline Parameter & $\begin{array}{c}\text { Lead-lag } \\
\text { PSS }\end{array}$ & $\begin{array}{c}\text { Original } \\
\text { PD-PSS }\end{array}$ & $\begin{array}{c}\text { Modified } \\
\text { PD-PSS }\end{array}$ \\
\hline $\begin{array}{c}\text { Max. } \\
\text { overshoot }\end{array}$ & 0.0073 & 0.0073 & 0.0073 \\
\hline $\begin{array}{c}\text { Settling } \\
\text { time }\end{array}$ & 3.5628 & 3.0514 & 3.0467 \\
\hline $\begin{array}{c}\text { Area under } \\
\text { curve }\end{array}$ & $4.0242 \mathrm{e}-5$ & $8.0917 \mathrm{e}-6$ & $-1.2693 \mathrm{e}-6$ \\
\hline
\end{tabular}

It can be seen that from (Fig. 16., and Table 16.) that all the maximum overshoot almost the same but the proposed modified PSO based PD-PSS have the smallest area under curve and settling time, which make the system faster in damping the LFOs when equipped with the proposed PSS than the other PSS. Figure 17. Shown active power responses system responses of machine M1 when this generator equipped with no PSS, CPSS, default PSO based PD-PSS, and modified PSO based PD-PSS.

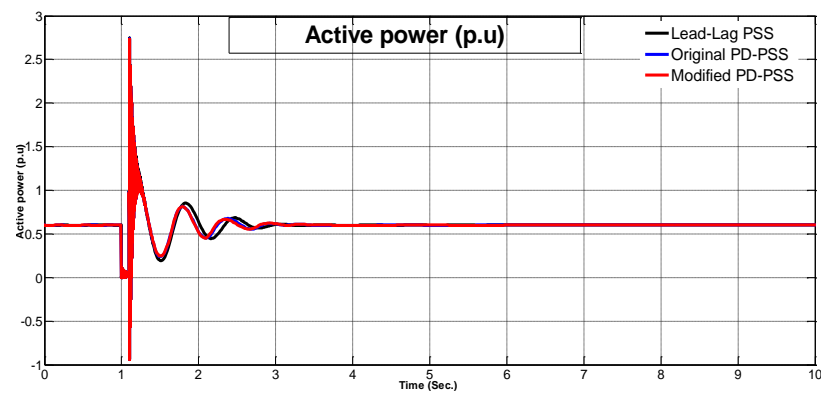

Fig. 17. Active power response of the system without PSS and with different PSS to 6-cycles three phase short circuit at light loading. 
The maximum overshoot, the settling time, and the area under curve of the power active system responses when generator M1 equipped with different PSS, which showed in the above figure are shown in Table 17.

Table 17. The Active Power Responses to 6-Cycles Three Phase Short Circuit near Generator M1 At Light Loading when the System Equipped with Different PSSs.

\begin{tabular}{|c|c|c|c|}
\hline Parameter & $\begin{array}{c}\text { Lead-lag } \\
\text { PSS }\end{array}$ & $\begin{array}{c}\text { Original } \\
\text { PD-PSS }\end{array}$ & $\begin{array}{c}\text { Modified } \\
\text { PD-PSS }\end{array}$ \\
\hline $\begin{array}{c}\text { Max. } \\
\text { overshoot }\end{array}$ & 2.7433 & 2.7387 & 2.7355 \\
\hline $\begin{array}{c}\text { Settling } \\
\text { time }\end{array}$ & 2.5785 & 2.7199 & 2.4826 \\
\hline $\begin{array}{c}\text { Area under } \\
\text { curve }\end{array}$ & 5.9942 & 5.9946 & 5.9941 \\
\hline
\end{tabular}

It can be seen that from (Fig. 17., and Table 17.) that all the area under curve almost the same, but the proposed modified PSO based PD-PSS have the smallest maximum overshoot and settling time, which indicate that the proposed PSS is robust than the other.

\section{Decreasing inertia constant}

In this study case the inertia constant decreased from 3.7Sec., to $2.5 \mathrm{Sec}$. at the normal loading condition and as the previous study cases. The Eigen-values of the system when the generator M1 equipped with lead-lag PSS, original PSO based PD-PSS, and modified PSO based PD-PSS at heavy loading are shown in Table 18.

Table 18. The Eigen-Values of the System with Different PSS at Normal Loading when H=2.5Sec.

\begin{tabular}{|c|c|c|c|}
\hline \multirow{4}{*}{ Eigen-values } & Lead-lag PSS & Original PSO based PD-PSS & Modified PSO based PD-PSS \\
\cline { 2 - 4 } & -880.76 & -888.03 & -894.11 \\
\cline { 2 - 4 } & -117.73 & $-65.43 \pm 59.88 \mathrm{i}$ & $-62.42 \pm 84.42 \mathrm{i}$ \\
\cline { 2 - 4 } & $-0.82 \pm 9.15 \mathrm{i}$ & $-1.78 \pm 5.27 \mathrm{i}$ & $-1.75 \pm 4.37 \mathrm{i}$ \\
\cline { 2 - 4 } & -12.30 & -20 & -20 \\
\hline
\end{tabular}

The Eigen-values of the system with different PSS proved that the proposed PSS is more reliable and robust than the other PSS in damping the LFOs.

\section{Small disturbance}

A small disturbance is simulated by applying $1 \%$ load step change of the full load is subjected at $1 \mathrm{Sec}$. The system responses to this disturbance when the generator M1 equipped with lead-lag PSS, original PSO based PDPSS, and modified PSO based PD-PSS, when using the speed deviation of the generator M1 are shown in fig. 18 .

The maximum overshoot, the settling time, and the area under curve of the speed deviation responses of the system with different PSS and without PSS are shown in Table 19.

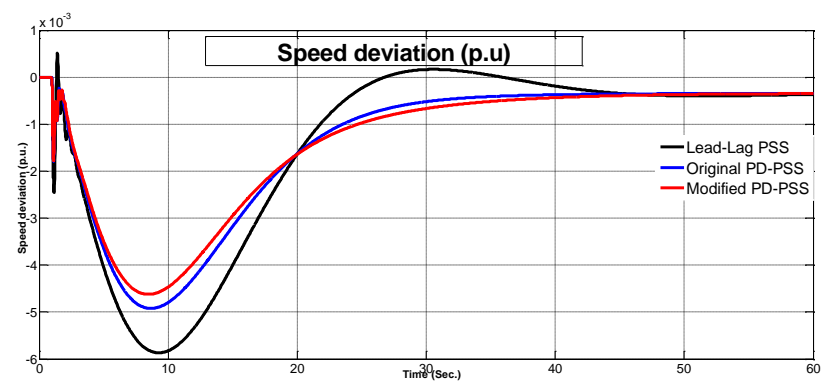

Fig. 18. Rotor speed deviation response of the system without PSS and with different PSS to $1 \%$ load step change at normal loading when $\mathrm{H}=2.5 \mathrm{Sec}$.

Table 19. The Rotor Speed Deviation Responses to Load Step Change 0.01 at Normal Loading Condition when M1 Inertia Constant H=2.5Sec., and the System Equipped with Different PSSs.

\begin{tabular}{|c|c|c|c|}
\hline parameter & Lead-lag PSS & Original PD-PSS & Modified PD-PSS \\
\hline Max. overshoot & $5.1582 \mathrm{e}-4$ & $4.9938 \mathrm{e}-7$ & $4.7652 \mathrm{e}-7$ \\
\hline Settling time & 41.8324 & 33.2813 & 34.0451 \\
\hline Area under curve & -0.0853 & -0.0831 & -0.0822 \\
\hline
\end{tabular}

The rotor speed deviation response of the system and its details in the table indicate that the system equipped with modified PSO based PD-PSS is more reliable and faster than the other in damping the LFOs with lower Maximum overshoot, and area under curve which improve the system stability. The active power responses of the system when generator M1 equipped with different PSS to 0.01 load step change shown in Fig. 19.

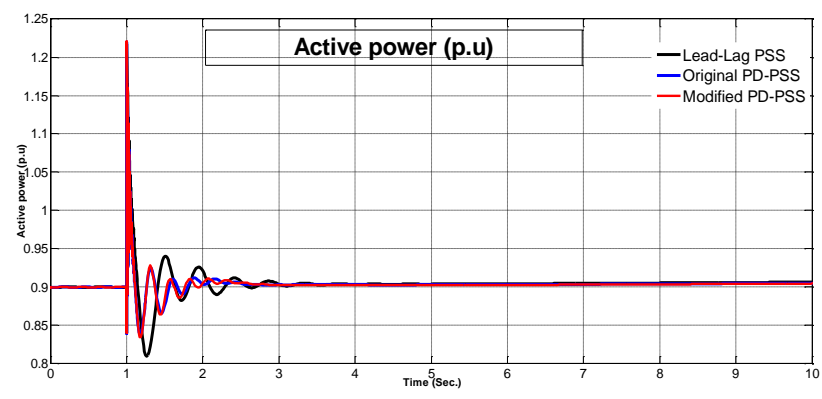

Fig. 19. Active power response of the system without PSS and with different PSS to 0.01 load step change at normal loading when $\mathrm{H}=2.5 \mathrm{Sec}$. 
The maximum overshoot, the settling time, and the area under curve of the power active system responses when generator M1 equipped with different PSS, which showed in the above figure are shown in Table 20.

Table 20. The Active Power Responses to Load Step Change 0.01 at Normal Loading Condition when M1 Inertia Constant H=2.5Sec., and the System Equipped with Different PSSs.

\begin{tabular}{|c|c|c|c|}
\hline Parameter & $\begin{array}{c}\text { Lead-lag } \\
\text { PSS }\end{array}$ & $\begin{array}{c}\text { Original } \\
\text { PD-PSS }\end{array}$ & $\begin{array}{c}\text { Modified } \\
\text { PD-PSS }\end{array}$ \\
\hline $\begin{array}{c}\text { Max. } \\
\text { overshoot }\end{array}$ & 1.2173 & 1.2198 & 1.2105 \\
\hline $\begin{array}{c}\text { Settling } \\
\text { time }\end{array}$ & 2.6919 & 1.9108 & 1.9124 \\
\hline $\begin{array}{c}\text { Area under } \\
\text { curve }\end{array}$ & 9.0418 & 9.0342 & 9.0306 \\
\hline
\end{tabular}

It can be seen from (Fig. 19., and Table 20.) that the proposed Modified PSO based PD-PSS is the most effective controller, and improve the stability of the system with the smallest area under curve, and maximum overshoot. The proposed PD-PSS improve the stability of the system higher than the other.

\section{Three phase short circuit}

A three phase short circuit to ground is applied to the system near to the generator M1 when the generator M1 is equipped with no PSS, lead-lag PSS, original PSO based PD-PSS, and modified PSO based PD-PSS. The short circuit applied at $1 \mathrm{Sec}$. and removed at $1.1 \mathrm{Sec}$. So that the short circuit is three phase 6-cycles. Figure 20. Shown rotor speed deviation system response of machine M1 when this generator equipped with no PSS, lead-lag PSS, original PSO based PD-PSS, and modified PSO based PD-PSS.

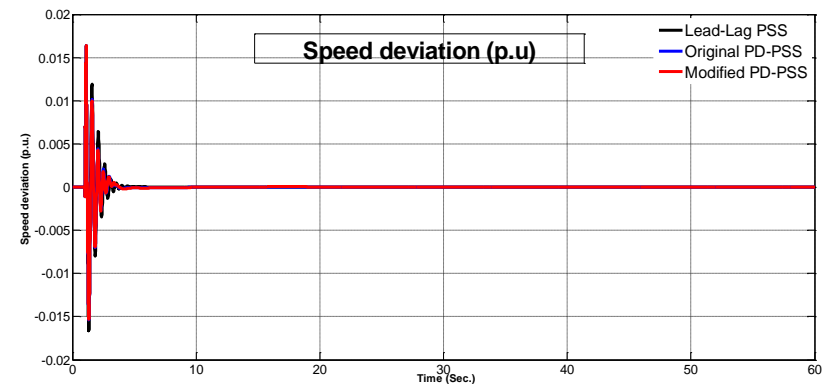

Fig. 20. Rotor speed deviation responses of the system without PSS and with different PSS to 6-cycles three phase short circuit at normal loading when $\mathrm{H}=2.5 \mathrm{Sec}$.

The maximum overshoot, the settling time, and the area under curve of the power active system responses when generator M1 equipped with different PSS, which showed in the above figure are shown in Table 21.

Table 21. The Rotor Speed Deviation Responses to 6-Cycles Three Phase Short Circuit near Generator M1 at Nominal Loading Condition when M1 Inertia Constant $\mathrm{H}=2.5 \mathrm{Sec}$., and the System Equipped with Different PSSs.

\begin{tabular}{|c|c|c|c|}
\hline Parameter & Lead-lag PSS & Original PD-PSS & Modified PD-PSS \\
\hline Max. overshoot & 0.0164 & 0.0164 & 0.0164 \\
\hline Settling time & 3.6130 & 3.4195 & 3.4024 \\
\hline Area under curve & $2.7444 \mathrm{e}-5$ & $-1.5860 \mathrm{e}-5$ & $-2.5731 \mathrm{e}-5$ \\
\hline
\end{tabular}

It can be seen that from (Fig. 20., and Table 21.) that all the maximum overshoot almost the same but the proposed modified PSO based PD-PSS have the smallest settling time, which make the system faster in damping the LFOs when equipped with the proposed PSS than the other PSS. Figure 21. Shown active power responses system responses of machine M1 when this generator equipped with no PSS, lead-lag PSS, original PSO based PD-PSS, and modified PSO based PD-PSS.

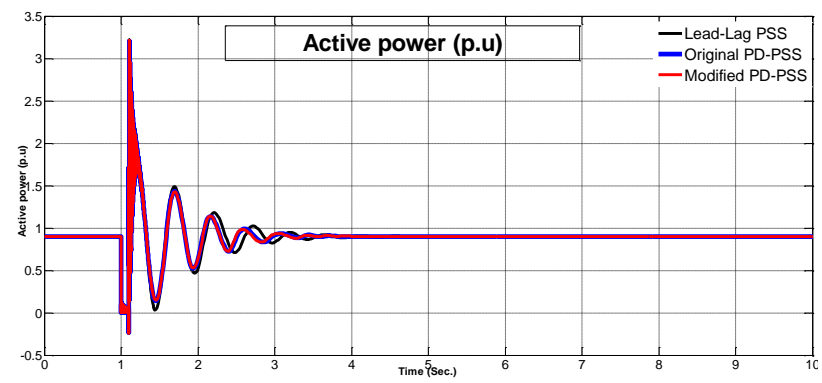

Fig. 21. Active power response of the system without PSS and with different PSS to 6-cycles three phase short circuit at normal loading when $\mathrm{H}=2.5 \mathrm{Sec}$.

The maximum overshoot, the settling time, and the area under curve of the power active system responses when generator M1 equipped with different PSS, which showed in the above figure are shown in Table 22.
Table 22. The Active Power Responses to 6-Cycles Three Phase Short Circuit near Generator M1 at Nominal Loading Condition when M1 Inertia Constant $\mathrm{H}=2.5 \mathrm{Sec}$., and the System Equipped with Different PSSs.

\begin{tabular}{|c|c|c|c|}
\hline Parameter & $\begin{array}{c}\text { Lead-lag } \\
\text { PSS }\end{array}$ & $\begin{array}{c}\text { Default } \\
\text { PD-PSS }\end{array}$ & $\begin{array}{c}\text { Modified } \\
\text { PD-PSS }\end{array}$ \\
\hline $\begin{array}{c}\text { Max. } \\
\text { overshoot }\end{array}$ & 3.2183 & 3.2064 & 3.2103 \\
\hline $\begin{array}{c}\text { Settling } \\
\text { time }\end{array}$ & 3.2248 & 2.9111 & 2.8792 \\
\hline $\begin{array}{c}\text { Area under } \\
\text { curve }\end{array}$ & 8.9927 & 8.9933 & 8.9932 \\
\hline
\end{tabular}

It can be seen that from (Fig. 21., and Table 22.) that all the area under curve almost the same, but the proposed modified PSO based PD-PSS have the smallest settling time, which indicate that the proposed PSS is robust than the other.

\section{CONCLUSION}

This paper proposes a method for power system stabilizer (PSS) gains tuning by using particle swarm optimization (PSO) technique. The tuning process makes the PSS more robust in damping low-frequency oscillations (LFOs). The PSS type used is proportionalderivative (PD) PSS. The damping boundary condition of 
the PSO algorithm is modified to make the PSO. This modification in PSO improves the searching process for the optimum values of PD-PSS gains and make it faster than the original PSO algorithm. The optimization process of the PD-PSS gains using eigenvalue as an objective function. The PD gains are estimated using a linear model and applied in the nonlinear model of an MATLAB Simulink program. The performance of the proposed PD-PSS is compared with the performance of the original PSO based PD-PSS, and the lead-lag PSS to investigate its effectiveness. The robustness of the proposed PD-PSS ensured when the study system is tested under different operating conditions, and inertia constant. The response of the proposed PD-PSS shows that the optimization process has brought a significant effect to improve the power system performance.

\section{APPENDIX A}

System parameters:

A) Generator $M 1$

$F=60 \mathrm{~Hz}, D \approx 0, M=7.4000 \mathrm{~s}, T_{d o}^{\prime}=1.01 \mathrm{~s}, X_{d}=$ 1.305 ,

$X_{d}^{\prime}=0.296, X_{\mathrm{q}}=0.474, K_{A}=200, T_{A}=0.01 \mathrm{Sec}$.

$P_{0}=0.9, Q_{0}=0.1464, \mathrm{~V}=1$.

B) $T-L$

$L=200 \mathrm{~km}, X_{L}=0.8737 \mathrm{e}-3 \mathrm{H} / \mathrm{Km}, X_{C}=13.33 \mathrm{e}-9 \mathrm{~F} / \mathrm{Km}$,

$V=500 \mathrm{MVA}, V_{L}=500 \mathrm{Kv}$

C) Loads

$1-P=0.4045 \mathrm{e} 9 \mathrm{~W}, Q_{L}=0.20225 \mathrm{e} 9 \mathrm{Var}$

2- $P=4.0450 \mathrm{e}+010 \mathrm{~W}, Q_{L}=2.0225 \mathrm{e}+010 \mathrm{Var}$

\section{REFERENCES}

[1] D. Sumina, N. Bulic, and M. Miscovic, "Parameter tuning of power system stabilizer using eigenvalue sensitivity," Electric Power Systems Research, vol. 81, no. 12, pp. 2171-2177, Dec. 2011.

[2] H. Bevrani, T. Hiyama, and H. Bevrani, "Robust PID based power system stabilizer: Design and real-time implementation," International Journal of Electrical Power and Energy Systems (IJEPES), vol. 33, no. 2, pp. 179-188, Feb. 2011.

[3] Y. Yu, Electric Power System Dynamics, Book, United Kingdom Edition published by ACADEMIC PRESS, INC. (LONDO) LTD. 1983.

[4] H. Mostafa, M. Elsharkawy, A. Emary, and K. Yassin, "Design and Allocation of Power System Stabilizers Using the Particle Swarm Optimization Technique for an Interconnected Power System," International Journal of Electrical Power and Energy Systems (IJEPES) Elsevier publisher, vol. 34, no. 1, pp. 57-65, Jan. 2012.

[5] Z. Jiang, "Design of a nonlinear power system stabilizer using synergetic control theory," Electric Power Systems Research, vol. 79, no. 6, pp. 855-862, Jun. 2009.

[6] F. Saleh, and M. Mahmoud, "Design of power system stabilizers using reduced-order models," Electric Power Systems Research, vol. 33, no 3, pp. 219-226, Jun. 1995.

[7] R. Gupta, B. Badyopadhyay, and A. Kulkarni, "Design of power system stabilizer for single machine system using robust fast output sampling feedback technique," Electric Power Systems Research, vol. 65, no. 3, pp. 247-257, Jun. 2003.

[8] Y. Peng, Q. Min, and H. Nouri, "Robust H2 power system stabilizer design using LMI technique," Proceeding of 2011 international conference on Modelling, Identification and Control (ICMIC), vol. 5, pp. 405-410, Jun. 2011.

[9] D. Sambariya, and R. Prasad, "Design of PSS for SMIB system using robust fast output sampling feedback technique," International conference on Intelligent Systems and Control (ISCO), vol. 7, pp. 166-171, Jan. 2013.

[10] D. Chaturvedi, and O. Malik, "Generalized neuron-based PSS and adaptive PSS," Control Engineering Practice, vol. 13, no. 12, pp. 1507-1514, Dec. 2005.

[11] G. Chen, O. Malik, Y. Qin, and G. Xu, "Optimization technique for the design of a linear optimal power system stabilizer," IEEE Transactions on Energy Conversion, vol. 7, no. 3, pp. 453-459, Sep. 1992.

[12] A. Soos, and O. Malik, "An optimal adaptive power system stabilizer," Power Engineering Society Summer Meeting, vol. 2, pp. 1219-1224, Jul. 1999.

[13] A. Soos, and O. Malik, "An H2 Optimal Adaptive Power System Stabilizer," IEEE Transaction Power Engineering Review, vol. 22, no. 2, pp. 59, Feb. 2002.

[14] J. Talaq, "Optimal power system stabilizers for multi machine systems," International Journal of Electric Power and Energy Systems, vol. 43, no. 1, pp. 793-803, Dec. 2012.

[15] Y. Park, J. Lee, S. Hyun, and K. Lee, "Asynchronous generator stabilizer based on a universal model," Electrical Power and Energy Systems, vol. 20, no. 6, pp. 435-442, 1998.

[16] F. HE, and M. GIBBARD, "Design of an Adaptive Bilinear Power System Stabilizer," Automatica, vol. 33, no. 4, pp. 663-668, April 1997.

[17] P. Dash, A. Liew, and B. Mishra, "An adaptive PID stabilizer for power systems using fuzzy logic," Electric Power Systems Research, vol. 44, no. 3, pp. 213-222, Mar. 1998.

[18] T. Liao, "Design of an adaptive nonlinear controller to improve stabilization of a power system," International Journal of Electrical Power and Energy Systems, vol. 21, no. 6, pp. 433-441, Aug. 1999.

[19] T. Abdelazim, and O. Malik, "An adaptive power system stabilizer using on-line self-learning fuzzy systems," IEEE transaction, Power Engineering Society General Meeting, vol. 3, pp. 1715-1720, Jul. 2003.

[20] E. Nechadi, M. Harmas, A. Hamzaoui, and N. Essounbouli, "A new robust adaptive fuzzy sliding mode power system stabilizer," International Journal of Electric Power and Energy Systems, vol. 42, no. 1,pp. 1-7, Nov. 2012.

[21] S. Radaideh, I. Nejdawi, and M. Mushtaha, "Design of power stabilizers using two level fuzzy and adaptive neuro-fuzzy inference systems," International Journal of Electric Power and Energy Systems, vol. 35, no. 1, pp. 4756, Feb. 2012.

[22] G. Rigatos, and P. Siano, "Design of robust electric power system stabilizers using Khaitonov's theorem," Mathematics and Computers in Simulation, vol. 82, no. 1, pp. 181-191, Sep. 2011.

[23] A. Sharaf, and T. Lie, "A hybrid neuro-fuzzy power system stabilizer," Proceedings of the Third IEEE Conference on Fuzzy Systems IEEE World Congress On Computational Intelligent, vol. 3, pp. 1608-1613, Jun. 1994. 
[24] A. Afzalian, and D. Linkens, "Training of neurofuzzy power system stabilizers using genetic algorithms," Electrical Power and Energy Systems, vol. 22, pp. 93-102, 2000.

[25] M. Salem, O. Malik, A. Mahgoub, and E. El-zahab, "Simple neuro-controller with a modified error function for a synchronous generator," International Journal of Electric Power and Energy Systems, vol. 25, no. 9, pp. 759-771, Nov. 2003.

[26] A. Sharma, and M. Kothari, "Intelligent dual power system stabilizer," Electric Power Systems Research, vol. 64, no. 3, pp. 257-267, Mar. 2003.

[27] V. Ravi, and K. Duraiswamy, "Effective optimization technique for power system stabilization using Artificial Bee Colony," International Conference on Computer Communication and Informatics (ICCCI), pp. 1-6, Jan. 2012.

[28] H. Alkhatib, and J. Duveau, "Dynamic genetic algorithms for robust design of multi-machine power system stabilizers," International Journal of Electric Power and Energy Systems, vol. 45, no. 1, pp. 242-251, Feb. 2013.

[29] W. Mamlouk, H. Mostafa, and M.A. Elsharkawy, "PSOBased PI Controller for Shunt APF in Distribution Network of Multi Harmonic Sources," International Journal of Intelligent Systems and Applications IJISA, Vol. 5, No. 8, pp. 54-66, July 2013.

[30] Hardiansyah, Junaidi, Yohannes MS, "Solving Economic Load Dispatch Problem Using Particle Swarm Optimization Technique," International Journal of Intelligent Systems and Applications IJISA, vol. 4, no. 12, Nov. 2012.

[31] M. Heydari,S.M. Hosseini,S.A. Gholamian, " Optimal Placement and Sizing of Capacitor and Distributed Generation with Harmonic and Resonance Considerations Using Discrete Particle Swarm Optimization," International Journal of Intelligent Systems and Applications IJISA, vol. 5, no. 7, Jun. 2013.

[32] Y. Abdel-Magid, and M. Dawoud, "Tuning of power system stabilizers using genetic algorithms," Electric Power Systems Research, vol. 39, no. 2, pp. 137-143, Nov. 1996.

[33] J. Lu, M. Nehrir, and D. Pierre, "A fuzzy logic-based selftuning power system stabilizer optimized with a genetic algorithm," Electric Power Systems Research, vol. 60, no. 2, pp. 77-83, Dec. 2001.

[34] S. Ghoshal, A. Chatterjee, and V. Mukherjee, "Bioinspired fuzzy logic based tuning of power system stabilizer," Expert Systems with Applications, vol. 36, no. 5, pp. 9281-9292, Jul. 2009.

[35] H. Alkhatib, and J. Duveau, "Dynamic genetic algorithms for robust design of multi-machine power system stabilizers," International Journal of Electric Power and Energy Systems, vol. 45, no. 1, pp. 242-251, Feb. 2013.

[36] P. Kundur, "Power System Stability and Control," McGraw-Hill, 1994.

[37] Q. Bai, "Analysis of Particle Swarm Optimization Algorithm," Computer and Information Science, vol. 3, no. 1, Feb. 2010.

[38] B. Birge, "Particle Swarm Optimization Toolbox," available at Matlab Online Help, http://www.MathWorks.com.

[39] D. Jovcic, and G. Pillai, "Analytical modeling of TCSC dynamics," IEEE Transactions on Power Delivery, vol. 20, no. 2, Apr. 2005.

[40] T. Huang, and A.S. Mohan, "A Hybrid Boundary Condition for Robust Particle Swarm Optimization," IEEE
Antennas and Wirless Propagation Letters, Vol.4, pp. 112117, 2005.

[41] J. Robinson, and Y. Rahmat-Samii, "Particle Swarm Optimization in Electromagnetics," IEEE Trans. Antennas and Propagation, Vol.52, No. 2, pp. 397-407, Feb. 2004.

\section{Authors' Profiles}

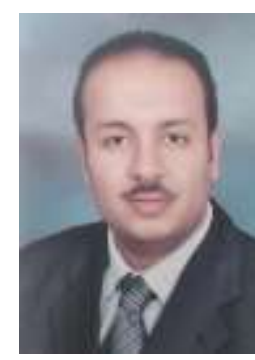

Nader M.A. Ibrahim received B.Sc. degree in electrical power systems and machines department in Faculty of Industrial Education from Suez Canal University, Suez, Egypt in 2009. During 2010-2011, he was studied pre-masters in the electrical power systems and machines department machine branch in Faculty of Industrial Education, Suez University, Suez, Egypt. Eng. Nader registered master in electrical power systems and machines. Currently, he is a demonstrator in electrical department at the Faculty of Industrial Education, Suez University, Suez, Egypt. His research interests are power system stability and operation, machine control, online and digital control in machines, applications of artificial intelligent techniques, like particle swarm optimization (PSO). His email is: Nader.abdelmohsen12@suezuniv.edu.eg.

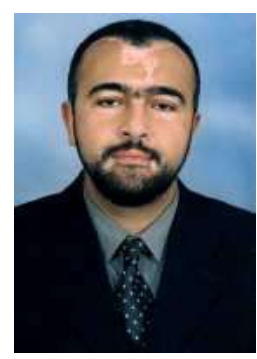

Hossam E.Mostafa (M'09): was born in Cairo, Egypt in 1965. He received his B.Sc., M.Sc. \& Ph. D. From Ain Shams University, Cairo, Egypt in 1987, 1994 and 1999 respectively. From 1991 to 2001 he was working in Egypt Air Company as second engineer. Since 2001, he has been a faculty member with the Electrical Department at the Faculty of Industrial Education, Suez Univ., Egypt. He is currently the chairman of the electrical \& electronic engineering technology department at Jubail Industrial Collage (JIC), Saudi Arabia. He supervised about 12 M.Sc. and $\mathrm{PhD}$ thesis (granted), and publish about 38 papers in journals and conferences. He has been a visiting Prof in many universities in Kuwait, Saudi Arabia, and Egypt. His major research interest is applying AI techniques in power system wide area control, protection, smart grids \& power quality. His email is: hossam.mostafa@ieee.org .

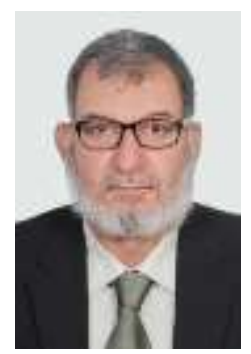

Hossam E.A. Talaat received the B.Sc and M.Sc. degrees from Ain Shams University, Cairo, Egypt in 1975 and 1980 respectively, and his Ph.D. degree from University of Grenoble, France in 1986. During 1999-2001. He is a reviewer of many international journals (IEEE, IET, Electric Power System Research, Electrical power and Energy systems, ...). He has supervised $40^{+}$Ph.D. and M.Sc. theses in the field of power system operation, control, stability and protection. He has taught tens of undergraduate and graduate courses in this field. He has authored and co-authored more than 70 technical papers and reports. He has accomplished several research projects as PI and as the investigator. He was the reviewer of a number of academic undergraduate and postgraduate programs for Egyptian and Arabic Universities. $\mathrm{He}$ is the Chairman of 2 IEC committees $(49 \& 93)$ and was a member of the Egyptian National board of Electricity and 
Energy Researches- Scientific Research and Technology Academy. He is the Chairman of the Middle East Conference on Power Systems MEPCON 2014 to be held on $23^{\text {th }}-25^{\text {th }}$ December 2014. He is interested in many research areas such as: Distributed Generation and Micro grids, Application of artificial intelligence techniques (Neural Networks, KnowledgeBased systems, Genetic Algorithms, and Fuzzy Logic) to Power System analysis, control, and protection; Real time applications to electrical power systems and machines; Application of optimal and adaptive control techniques for the enhancement of power system stability. His email is: hossam_talaat@eng.asu.edu.eg.

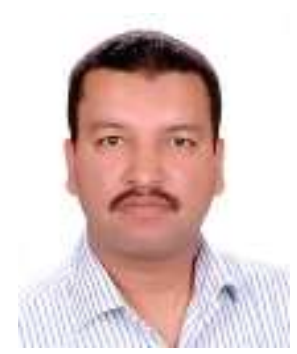

Ali H. Kasem Alaboudy (S'07, M'09) received the M.Sc. and Ph.D. degrees in electrical engineering from Minia University, El-Minia, Egypt in 2002 and 2009 respectively. During 20062008, he was a visiting scholar in the Department of Electrical \& Computer Engineering, University of Waterloo, Ontario, Canada. During 2010, Dr. Kasem was a Post Doctorate Fellow with the Masdar Institute of Science and Technology in Abu Dhabi, UAE. Currently, he is an associate professor at the Faculty of Industrial Education, Suez University, Suez, Egypt. His research interests are wind energy: control and power quality issues; distributed generation, and power system operation.

How to cite this paper: Nader M.A. Ibrahim, Hossam E. M. Attia, Hossam E.A. Talaat, Ali H. Kasem Alaboudy,"Modified Particle Swarm Optimization Based Proportional-Derivative Power System Stabilizer", International Journal of Intelligent Systems and Applications (IJISA), vol.7, no.3, pp.62-76, 2015. DOI: $10.5815 /$ ijisa.2015.03.08 